DOI: $10.21802 /$ artm.2020.3.15.74.

УДК 616.381-002-001-089

\title{
ЛАПАРОСТОМА В ХІРУРГІЧНОМУ ЛІКУВАННІ ХВОРИХ НА ГОСТРУ НЕПРОХІДНІСТЬ ТОНКОЇ КИШКИ
}

\author{
І.Я. Дзюбановський, В.В. Бенедикт, А.М. Продан
}

Тернопільський національний медичний університет імені І.Я. Горбачевського, кафедра хірургії ННІ ПО, м. Тернопіль, Украӥна, ORCID ID: 0000-0001-8852-3938, ORCID ID: 0000-0002-7650-1771, ORCID ID: 0000-0002-6052-192X, e-mail: benedyktvv@gmail.com

Резюме. Цілі: покращення результатів хірургічного лікування пацієнтів на ГНТК за допомогою використання лапаростомії.

Методи. Нами здійснено комплексне обстеження 221 хворого на ГНТК, яким проведені різні хірургічні втручання, спрямовані на усунення непрохідності. Лікування ГНТК на фоні гострого поширеного перитоніту в цій групі проводили у 17 (7,69 \%) хворих. Оцінено стан моторно-евакуаторної функції травного каналу, стан неспецифічної резистентності організму. В післяопераційному періоді визначали внутрішньочеревний тиск (I. Kron et al. (1998)).

Результати. У 9 пацієнтів, хворих на ГНТК, на тлі поширеного гнійно-фібринозного перитоніту сформовано первинний ентеро-ентероанастомоз з лапаростомою за власною методикою. При задовільному перебігу захворювання (за клінічними, сонографічними критеріями відновлення моторно-евакуаторної функції травного каналу) шляхом розсічення синтетичних ниток проводилося поетапне видалення по 2-3 ПХВ трубки за добу і перфорованої плівки за допомогою інтраопераційно накладеної лігатури, якою вона була прошита під час операції. За нашими даними, у хворих на ГНТК в умовах поширеного перитоніту при наявності післяопераційного парезу, при накладані лапаростоми інтраабдомінальний тиск в середньому складав $(12,52 \pm 3,38)$ мм рт. ст. $(\mathrm{p}<0,05)$.

Висновки. Використання лапаростоми у хворих на ГНТК в умовах поширеного перитоніту сприяє профілактиці розвитку компартмент синдрому, аерації черевної порожнини і покращенню перебігу післяопераційного періоду, також дозволяє проводити контроль за станом органів черевної порожнини після операції, зменшити кількість релапаротомій і загального знечулення під час закриття лапаростоми.

Ключові слова: лапаростома, гостра непрохідність тонкої кишки.

Вступ. Однією $з$ причин незадовільних результатів хірургічного лікування пацієнтів на гостру непрохідність тонкої кишки (ГНТК) може бути розвиток компартмент синдрому та поліорганної недостатності $[4,10]$. Це спонукає до виконання релапаротомії, яка своєю чергою додатково ускладнює перебіг захворювання [9]. Однією з причин такого стану, на нашу думку, є вибір неадекватного методу завершення операції. Актуальним i дотепер $\epsilon$ вислів И.И.Грекова про те, що тактика ушивання лапаротомної рани у хворих на поширений перитоніт наглухо “... весьма красива, увлекательна и удобна, но она в случае неудачи может стоить больному жизни”.

Порушення функції травного каналу у хворих на ГНТК є однією з основних причин незадовільних результатів в лікуванні цих пацієнтів. Звільнення тонкої кишки (ТК) від іiї вмісту під час операції та створення безперешкодного його відтоку в післяопераційному періоді досягається інтубацією цього органу $[3,11,6,12]$. Однак, на нашу думку, одним 3 негативних факторів, які можуть сприяти тяжкому перебігу післяопераційного періоду у хворих на ГНТК, $є$ підвищення внутрішньо-абдомінального тиску (ВОТ) $[13,14,15]$. Цей маловивчений компонент в дослідженні патогенезу розвитку порушень моторики травного каналу у хворих на ГНТК має не тільки місцеве значення, а й впливає на загальний гомеостаз хворого після операції. Ми згідні з думкою Г. Мондора (1947) [8] про те, що притримуватися однієї клінічної схеми, це значить приректи себе в багатьох випадках на помилки, і тому вибір способу завершення операції повинен бути із врахуванням не тільки діагнозу, а й наявної конкретної інтраопераційної ситуації.

Мета дослідження. Метою нашого дослідження $\epsilon$ покращення результатів хірургічного лікування пацієнтів на ГНТК за допомогою використання лапаростомії.

Матеріали та методи дослідження. Нами проведено комплексне обстеження 221 хворого на ГНТК, яким проведені різні хірургічні втручання, спрямовані на усунення непрохідності. Характер виконаних операцій у оперованих хворих був наступним: малоінвазивні втручання - 25 (11,31 \%), лапаротомія і роз'єднання спайок без декомпресії травного каналу - 67 (30,32 \%) хворих, роз'єднання спайок 3 декомпресією травного каналу - у 107 (48,42 \%) хворих і резекція ТК з декомпресією - в $22(9,95 \%)$ випадках. В останню групу пацієнтів, яким виконано ліквідацію непрохідності шляхом резекції ділянки ТК, увійшли хворі зі странгуляційною непрохідністю ТК - 16 (72,73 \%), тонко-тонкокишковою інвагінаці- 
єю - 2 (9,09 \%), обтурацією жовчним конкрементом 3 некрозом стінки ТК - $3(13,64 \%)$, зі стороннім тілом черевної порожнини з некрозом ділянки ТК - 1 (4,55 $\%)$.

Лікування ГНТК на фоні гострого поширеного перитоніту в групі з резекцією проводили у 17 $(77,27 \%)$ хворих. Одномоментна декомпресія ТК проведена усім 22 (100\%) пацієнтам інтраопераційно. У 8 (36,36 \%) осіб операцію завершено накладанням кінцевої ентеростоми (ілеостоми), у 9 (40,91\%) пацієнтів сформовано первинний ентероентероанастомоз з лапаростомою за власною методикою.

Проводилося комплексне обстеження оперованих хворих за допомогою загальноприйнятих методів, а також дослідження серцево-судинної і легеневої систем, стан моторно-евакуаторної функції травного каналу, визначали індекс коморбідності (Charlson M.E. et ol., 1987) [2], оцінювали стан неспецифічної резистентності організму за допомогою паличкоядерно-лімфоцитарного індексу (ПЛІ) [1], рівень інтоксикації - за допомогою лейкоцитарного індексу інтоксикації (ЛІІ) [5], визначали по шкалі ASA анестезіологічно-операційний ризик [7].

В післяопераційному періоді визначали внутрішньочеревний тиск (ВОТ). Цей показник ми досліджували непрямим методом згідно з рекомендаціями Всесвітнього товариства 3 вивчення наявності компартмент синдрому шляхом визначення його в сечовомy міхурі за I. Kron et al. (1998), M. Cheatham et al. (1998).

Крім цього, проведено ретроспективний аналіз 32 медичних карт стаціонарних хворих із несприятливим перебігом ГНТК.

Результати дослідження та їх обговорення. При проведені ретроспективного аналізу хворих на ГНТК з несприятливим перебігом захворювання було встановлено, що хронічна супутня патологія (індекс коморбідності 5,5-6,07) була виявлена у 30 пацієнтів $(93,8 \%)$; операційно-анестезіологічний ризик за шкалою ASA IV-V класу спостерігався у 87,5 \% хворих; вибір неадекватного для конкретної операційної ситуації методу декомпресії травного каналу - у 25 хворих (78,13 \%); помилкова інтерпретація життєздатності ТК - в 12 випадках (37,5 \%). У 96,67 \% випадків була відсутність i пригнічення моторноевакуаторної функції травного каналу, що також сприяло летальному наслідку в результаті підвищення інтраабдомінального тиску та появи синдрому поліорганої недостатності в 26 (81,25 \%) хворих. Більш ніж в половини оперованих хворих (56,25 \%) летальність наступила в перші три доби після операції. Третя і п’ята доба після операції являлися найбільш несприятливими в перебігу післяопераційного періоду у хворих цієї групи. Лапаростому використовували тільки у одного хворого під час первинної операції і в двох - під час релапаротомії.

У 22 випадках, що склали 9,96 \% зі всіх оперованих 3 сприятливим перебігом ГНТК, 45,45 \% хворих були у віці до 60 років, інші - у віці 60 і більше років. Цілком зрозуміло, що такий віковий розподіл впливає на перебіг захворювання після операції.
Супутні захворювання мали місце у 17 (77,27 \%) пацієнтів. Індекс коморбідності був наступним: до 59 років - 1,7, у віці - 60-74 років - 4,33 бали і у віці 7589 років - 5,5 балів. У стадії компенсації функціонального стану організму хворого поступило тільки 5 $(22,43 \%)$ пацієнтів в другому періоді перебігу ГНТК. У стадії декомпенсації функціонального стану - 17 (77,28\%) хворих, з них 14 (82,36 \%) в третьому періоді перебігу захворювання.

У хворих на ГНТК, яким в згодом була виконана резекція ураженої ділянки ТК, до операції спостерігалися суттєві порушення рухової активності травного каналу у вигляді пригнічення або відсутності моторики - у 81,82 \% хворих, іiі підсилення - в 13,64 \% пацієнтів і в одному випадку - рухові порушення ТК ще не спостерігалися.

У хворих цієї групи зсув паличкоядерних нейтрофілів в лейкоцитарній формулі крові був в 2,79 раз більший від верхньої межі норми, ЛІІ зростав майже в 6 разів, а ПЛІ - майже в 3 рази. Це пояснюється значною інтоксикацією у хворих на ГНТК внаслідок некрозу ділянки ТК і інтоксикацією внаслідок порушень моторно-евакуаторної функції травного каналу, що призводить до напруження неспецифічної резистентності організму пацієнта.

Наявність супутньої патології у хворих на фоні стадії перебігу захворювання сприяло погіршенню компенсаторних можливостей організму пацієнта і збільшенню ступеня операційно-анестезіологічного ризику (ASA). 3 першим ступенем було 5 (22,73\%) Хворих, 3 другим - 5 (22,73\%), з третім і четвертим 9 (40,91 \%) і 3 (13,63 \%) випадків відповідно.

У 9 пацієнтів цієї групи, хворих на ГНТК, на тлі поширеного гнійно-фібринозного перитоніту сформовано первинний ентеро-ентероанастомоз 3 лапаростомою за власною методикою (рис. 1).

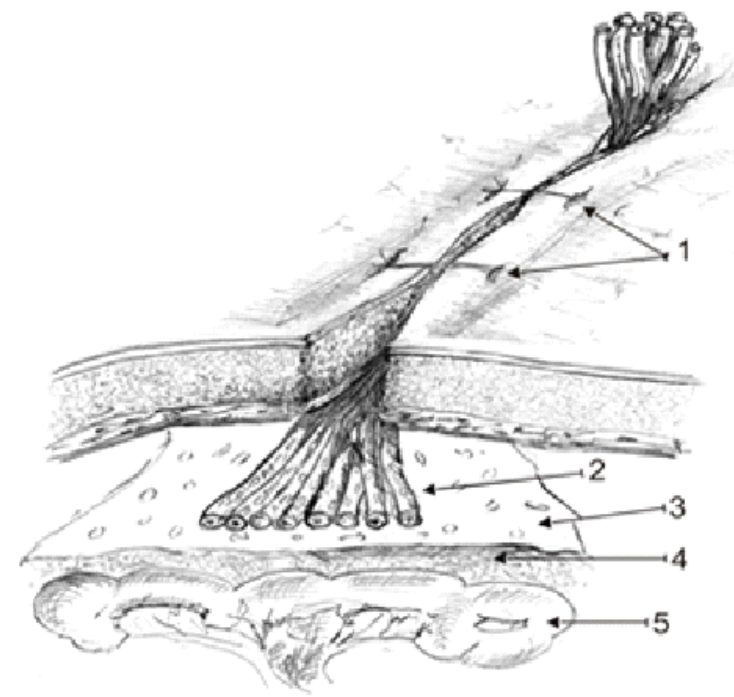

Рис. 1. Спосіб лапаростомії у хворих на гостру непрохідність тонкої кишки, ускладнену перитонітом (опис в тексті)

Перед ушиванням черевної порожнини і після проведення іiі дренування на великий сальник (4) або при його відсутності на петлі тонкої кишки (5) накладали перфоровану гладку плівку (3), яку попе- 
редньо прошивали лігатурою і виводили через нижній розріз лапаростоми. Зверху плівки укладали частокіл з 6-8 ПХВ трубок (2), перед цим їх прошивши синтетичною ниткою (№ 5-6) у трьох місцях (1). За допомогою цих ниток фіксували ПХВ трубки до черевної стінки шляхом прошивання передньої стінки живота зсередини назовні. При задовільному перебігу захворювання (за клінічними, сонографічними критеріями відновлення моторно-евакуаторної функції травного каналу) шляхом розсічення синтетичних ниток проводилося поетапне видалення по 2-3 ПХВ трубки за добу і перфорованої плівки за допомогою інтраопераційно накладеної лігатури, якою вона була прошита під час операції.

Перевагою запропонованої лапаростоми $є$ відсутність необхідності виконання повторної лапаротомії для закриття лапаростоми, профілактика розвитку інтраабдомінальної гіпертензії, аерація черевної порожнини, можливий контроль за станом черевної порожнини i, при необхідності, - легкість проведення повторної санації.

За нашими даними, у хворих на ГНТК в умовах поширеного перитоніту, при наявності післяопераційного парезу при накладанні лапаростоми, інтраабдомінальний тиск в середньому складав $(12,52 \pm 3,38)$ мм рт. ст. $(\mathrm{P}<0,05)$.

Крім цього, після операції на фоні загальноприйнятої терапії нами для раннього відновлення моторно-евакуаторної функції травного каналу використовувалась корегувальна медикаментозна терапія iз застосуванням есенціальних фосфоліпідів, антиоксидантів, енергетичних донаторів, препаратів кальцію або його антагоністів залежно від характеру перистальтики в післяопераційному періоді.

Отже, оцінюючи стан моторно-евакуаторної функції травного каналу у пацієнтів, ми встановили, що при ГНТК навіть в умовах перитоніту та виконаної резекції ТК з формуванням ентеростом і лапаростом використання в післяопераційному періоді комплексної корегувальної медикаментозної терапії призводить до іï відновлення на 2-3 добу, що дозволяло призначати раннє ентеральне харчування, зменшити рівень інтоксикації і покращити якість життя пацієнтів у ранньому післяопераційному періоді.

3 огляду на наш досвід лікування хворих на ГНТК покази до використання лапаростоми можуть бути розширені, зокрема ними є: наявність гострого гнійного поширеного перитоніту; неповна декомпресія ТК під час операції із-за технічних труднощів; невпевненість у герметичності сформованого анастомозу, декомпенсований функціональний стан хворого, ожиріння і складність завершення операції шляхом ушивання лапаротомної рани наглухо і вірогідність підвищення внутрішньоабдомінального тиску.

\section{Висновки:}

1. Використання лапаростоми - це відсутність необхідності виконання повторної лапаротомії для закриття лапаростоми, профілактика розвитку компартмент синдрому, аерація черевної порожнини, можливий контроль за станом черевної порожнини i, при необхідності, - легкість проведення повторної санації.
2. Запропонований спосіб лапаростоми дозволяє проводити контроль за станом органів черевної порожнини після операції, зменшити кількість релапаротомій і загального знечулення під час закриття лапаростоми, що суттєво покращує результати хірургічного лікування пацієнтів на гостру непрохідність тонкої кишки в умовах поширеного перитоніту.

\section{Reference:}

1. Benedykt VV. Pro znachennia monitorynhu stanu nespetsyfichnoi rezystentnosti orhanizmu u khvorykh na hostru nepmrokhidnist kyshky. Zbirnyk materialiv XVI zizdu Vseukrainskoho likarskoho tovarystva. Kamianets-Podilskyi, 2017. P. 216.

2. Charlson ME, Pompei P, Ales KL, MacKenzie CR. A new method of classifying prognostic comorbidity in longitudinal studies: development and validation. J Chronic Dis. 1987; 40(5):373-83.

3. de $\mathrm{Li} \mathrm{C}$, Li RH, Tian Q. Efficacy of intestinal decompression with long nasointestinal tube and selective contrast radiography in the treatment of small bowel obstruction in elderly patients. Minerva Chir. 2016; 71(2):85-90.

4. Hecker A, Hecker B, Hecker M, Riedel JG, Weigand MA, Padberg W. Acute abdominal compartment syndrome: current diagnostic and therapeutic options. Langenbecks Arch Surg. 2016; Feb, 401(1):1524.

5. Kalf-Kalyf YaYa. O hematolohycheskoi dyfferentsyatsyy razlychnykh form y faz ostroho appendytsyta. Khyrurhyia. 1947; 7:40-43.

6. Karakonstantis S, Kalemaki D. Symptomatic relief as an outcome in studies of nasogastric decompression in small bowel obstruction. Am J. Emerg. Med. 2018; 36(6):1109-1110.

7. Little JP. Consistency of ASA grading. Anaesthesia. 1995; 50(7):658-659.

8. Mondor H. Neotlozhnaia dyahnostyka. Rypol Klassyk, 2013. P.406.

9. Rogers WK, Garcia L. Intra-Abdominal Hypertension, Abdominal Compartment Syndrome, and the Open Abdomen. Chest. 2017; Aug, 2.

10. Thabet FC, Ejike JC. Intra-abdominal hypertension and abdominal compartment syndrome in pediatrics. A review. J Crit Care. 2017; Jun, 7. 41:275-282.

11. Ullah MA, Rahman MA, Chowdhury LH, Mohammed S, Hasan MI. Outcome of upper gastrointestinal surgery with or without nasogastric intubation. Mymensingh Med. J. 2017; 26(3):650-657

12. VijayGanapathy S, Karthikeyan VS, Mallya A, Poonawala A, Keshavamurthy R. Nasogastric tube as abdominal pressure sensor in urodynamics-proof of concept of a novel approach. Neurourol Urodyn. 2018; 37(2):785-791.

13. Sánchez-Miralles A, Castellanos G, Badenes R, Conejero R. Abdominal compartment syndrome and acute intestinal distress syndrome. Med Intensiva. 2013; 37(2):99-109. Review. Spanish

14. Lee RK. Intra-abdominal hypertension and abdominal compartment syndrome: a comprehensive overview. Crit Care Nurse. 2012; 32(1):19-31.Review

15. Luckianow GM, Ellis M, Governale D, et al. Abdominal compartment syndrome: risk factors, diagno- 
sis, and current therapy. Crit Care Res Pract 2012;908169. doi:10.1155/2012/908169. (в такому форматі цитована ця стаття в іншому журналі, сторінки також не сказані, адже стаття оригінально скачується з нумерацією сторінок від 1 до 8)

\section{УДК 616.381-002-001-089 \\ ЛАПАРОСТОМА В ХИРУРГИЧЕСКОМ ЛЕЧЕ- НИИ БОЛЬНЫХ С ОСТРОЙ НЕПРОХОДИМО- СТЬЮ ТОНКОЙ КИШКИ}

\section{И.Я. Дзюбановский, В.В. Бенедикт, А.М. Продан}

Тернопольский национальньй медицинский университет имени И.Я. Горбачевского, кафедра хирургии УНИ ПО,

2. Тернополь, Украина,

ORCID ID: 0000-0001-8852-3938,

ORCID ID: 0000-0002-7650-1771,

ORCID ID: 0000-0002-6052-192X,

e-mail: benedyktvv@gmail.com

Резюме. Цели: улучшение результатов хирургического лечения пациентов с ОНТК посредством использования лапаростомы.

Методы. Нами проведено комплексное обследование 221 больного с ОНТК, которым проведены различные хирургические вмешательства, направленные на устранение непроходимости. Лечение ОНТК на фоне острого распространенного перитонита в этой группе проводили у 17 (7,69 \%) больных. Оценено состояние моторно-эвакуаторной функции ЖКТ, состояние неспецифической резистентности организма. В послеоперационном периоде определяли внутрибрюшное давление (I. Kron et al. (1998)).

Результаты. В 9 пациентов с ОНТК на фоне распространенного гнойно-фибринозного перитонита сформирован первичный энтеро-ентероанастомоз с лапаростомой по собственной методике. При удовлетворительном течении заболевания (по клиническим, сонографическим критериям восстановления моторно-эвакуаторной функции ЖКТ) путем рассечения синтетических нитей, проводилось поэтапное удаление по 2-3 ПХВ трубки в сутки и перфорированной пленки с помощью интраоперационно наложенной лигатуры, какой она была прошита во время операции. По нашим данным, у больных с ОНТК в условиях распространенного перитонита при наличии послеоперационного пареза, при наложении лапаростомы интраабдоминальное давление в среднем составляло $(12,52 \pm 3,38)$ мм рт. ст. $(\mathrm{p}<0,05)$.

Выводы. Использование лапаростомы у больных с ОНТК в условиях распространенного перитонита способствует профилактике развития компартмент синдрома, аэрации брюшной полости и улучшению течения послеоперационного периода, также позволяет проводить контроль над состоянием органов брюшной полости после операции, уменьшить количество релапаротомий и общего обезболивания при закрытии лапаростомы.
Ключевые слова: лапаростома, острая непроходимость тонкой кишки.

\section{UDC 616.381-002-001-089
LAPAROSTOMA IN A SURGICAL TREATMENT OF ACUTE OBSTRUCTION OF THE SMALL INTESTINE}

\author{
I.Ya. Dzubanovsky, V.V. Benedykt, A.M. Prodan
}

I.Horbachevsky Ternopil National Medical University, Department of Surgery Postgraduate Faculty, Ternopil, Ukraine, ORCID ID: 0000-0001-8852-3938,

ORCID ID: 0000-0002-7650-1771, ORCID ID: 0000-0002-6052-192X, e-mail: benedyktvv@gmail.com

Abstract. Aim: Improvement of the results of surgical treatment of patients with AOSI by using laparostomy.

Methods. We conducted a comprehensive examination of 221 patients with AOSI, who underwent various surgical interventions aimed at eliminating obstruction. Treatment of AOSI against the background of acute widespread peritonitis in this group was performed in $17(7.69 \%)$ patients. The state of the motor-evacuation function of the gastrointestinal tract, the state of nonspecific resistance of the body were evaluated. In the postoperative period, intra-abdominal pressure was determined (I. Kron and co- authors (1998)).

Results. A retrospective analysis of patients with acute obstruction of small intestine with an unfavorable course of the disease revealed that chronic comorbidity (comorbidity index 5.5-6.07) was detected in 30 patients (93.8\%); surgical and anesthesia risk according to the ASA IV-V scale was observed in $87.5 \%$ of patients; the choice of inadequate for a particular surgical situation method of decompression of the digestive tract in 25 patients $(78.13 \%)$; misinterpretation of small bowel viability - in 12 cases $(37.5 \%)$. In $96.67 \%$ of cases there was a lack and suppression of motor-evacuation function of the digestive tract, which also contributed to the lethal outcome due to increased intra-abdominal pressure and the appearance of multiple organ syndrome in 26 $(81.25 \%)$ patients. Laparostomy was used in only one patient during primary surgery and in two during relaparotomy. In patients with AOSI who were subsequently resected the affected area of the digestive canal before surgery, there were significant violations of motor activity of the digestive tract in the form of depression or lack of motility - in $81.82 \%$ of patients, its strengthening - in $13.64 \%$ of patients and in one case - motor disorders of digestive tract have not yet been observed.

In 9 patients with acute obstruction of small intestine on the background of widespread purulentfibrinous peritonitis formed a primary enteroenteroanastomosis with laparostomy according to their own method.

Before suturing the abdominal cavity and after its drainage on the large omentum or, in its absence, on 
the loop of the small intestine was applied perforated smooth film, which was previously stitched with ligature and removed through the lower incision of the laparostomy. Fences of 6-8 PCV tubes were laid on top of the film, before stitching them with synthetic thread in three places. Using these threads, the PCV tube was fixed to the abdominal wall by stitching the anterior abdominal wall from the inside out. In a satisfactory course of the disease (according to clinical, sonographic criteria for restoration of motor-evacuatory function of the digestive tract) by dissection of synthetic fibers, was performed gradual removal of 2-3 PCV tubes per day and perforated film using intraoperatively ligature, during which it was stitched. The advantage of the proposed laparostomy is the absence of the need for repeated laparotomy to close the laparostomy, prevention of intra-abdominal hypertension, aeration of the abdominal cavity, possible control over the condition of the abdominal cavity and, if necessary, the ease of re-rehabilitation.

Conclusions. The use of a laparostomy in patients with AOSI in conditions of widespread peritonitis helps to prevent the development of compartment syndrome, aeration of the abdominal cavity and improves the course of the postoperative period, also allowsto monitor the state of the abdominal organs after surgery, reduce the number of relaparotomies and general anesthesia when closing the laparostomy.

Keywords: laparostomy, acute obstruction of the small intestine.

Стаття надійшла в редакцію 01.06.2020 p. 